\title{
Manifestações Reumáticas da Síndrome de Imunodeficiência Adquirida (AIDS)**)
}

\author{
Rheumatic Manifestations of the Acquired \\ Immunodeficiency Syndrome (AIDS)
}

\author{
Rodrigo Siqueira-Batista ${ }^{(1)}$, Andréia Patrícia Gomes ${ }^{(2)}$, Marcelo Souto Nacif ${ }^{(3)}$, Juliana Elvira Herdy Guerra ${ }^{(4)}$, \\ Cristiano Ramos Monte-Alto( ${ }^{(4)}$, Olímpia Alves Teixeira Lima ${ }^{(4)}$, Daniela Silva de Amorim ${ }^{(5)}$ e \\ Nelson Luís de Maria Moreira ${ }^{(6)}$
}

\section{RESUMO}

Diferentes síndromes reumáticas e fenômenos auto-imunes já foram associados à infecção pelo vírus da imunodeficiência humana (HIV), quer pela maior freqüência de adoecimento, quer pela maior gravidade. Ademais, em muitos casos, sintomas e sinais da doença reumática estão presentes na abertura do quadro de infecção pelo HIV (como na síndrome de soroconversão) ou da síndrome de imunodeficiência adquirida (AIDS). O reconhecimento deste horizonte é da maior importância para a prática do reumatologista, tornando-se altamente necessário ampliar a familiaridade com estes conceitos. Revisitar as interseções reumatológicas da infecção pelo HIV - enfatizando-se situações como as espondiloartropatias soronegativas, as artralgias, as artrites infecciosas, fibromialgia, miopatias, vasculites, síndrome linfocítica infiltrante difusa, lúpus eritematoso sistêmico e fenômenos auto-imunes - é, pois, o objetivo do presente artigo.

Palavras-chave: manifestações musculoesqueléticas, manifestações reumáticas, vírus da imunodeficiência humana.

\begin{abstract}
Different rheumatic syndromes and auto-immune phenomena have already been associated with the infection by the human immunodeficiency virus (HIV), either by the higher frequency of the disease or by the greater severity. Furthermore, in many cases, symptoms and signs of rheumatic disease are present at the beginning of the infection condition by HIV (as in the serum conversion) or the Acquired Immunodeficiency Syndrome (AIDS). Recognition of these possibilities is of fundamental importance to the rheumatologist practice and is necessary to have familiarity with these concepts. Revisiting the rheumatologic intersections of the infection by HIV - emphasizing situations such as seronegative spondyloarthropathies, arthralgia, infectitious arthritis, fibromyalgia, myopathy, vasculitis, difuse infiltranting lymphocytic syndrome systemic lupus erythematous and auto-immune phenomena - is then, the aim of the present article.
\end{abstract}

Keywords: Musculoskeletal manifestations; rheumatic manifestations; human immunodeficiency virus.

* Disciplina de Clínica Médica, Faculdade de Medicina de Teresópolis, Fundação Educacional Serra dos Órgãos (FESO), RJ. Recebido em 10/10/2002. Aprovado, após revisão, em 9/9/2004.

1. Professor Titular da Disciplina de Clínica Médica, Faculdade de Medicina de Teresópolis, Fundação Educacional Serra dos Órgãos (FESO), RJ. Professor Titular da Disciplina de Filosofia, Curso de Graduação em Ciência da Computação (FESO). Coordenador do Núcleo de Estudos em Filosofia e Saúde (NEFISA) - FESO. Médico da Comissão de Bioética e do Serviço de Clínica Médica, Hospital Universitário Clementino Fraga Filho, Universidade Federal do Rio de Janeiro (UFRJ). Infectologista do Centro de Vigilância Epidemiológica (CVE) da Secretaria de Estado de Saúde - RJ. Mestre em Medicina pela UFRJ e em Filosofia pela Pontifícia Universidade Católica do Rio de Janeiro (PUC-Rio). Doutorando em Ciências, Escola Nacional de Saúde Pública (ENSP), Fundação Oswaldo Cruz (FIOCRUZ).

2. Professora Titular da Disciplina de Clínica Médica, Faculdade de Medicina de Teresópolis, Fundação Educacional Serra dos Órgãos (FESO). Professora Titular da Disciplina de Doenças Infecciosas e Parasitárias - FESO. Especialista em Doenças Infecciosas e Parasitárias, Universidade Federal do Rio de Janeiro. Mestre em Medicina Tropical, Instituto Oswaldo Cruz, Fundação Oswaldo Cruz (FIOCRUZ). Columnista Médico Experto de la Sociedad Iberoamericana de Información Científica. Médica Infectologista do Centro de Vigilância Epidemiológica (CVE) da Secretaria de Estado de Saúde - RJ. Coordenadora do Núcleo de estudos em Tuberculose (NET) - FESO.

3. Professor Auxiliar da Disciplina de Radiologia, Faculdade de Medicina de Teresópolis - FESO. Membro da Comissão de Residência Médica da Sociedade Brasileira de Radiologia. Mestrando em Medicina/Radiologia, UFRJ

4. Diplomado(a) em Medicina, Fundação Educacional Serra dos Órgãos, RJ, Brasil.

5. Diplomanda em Medicina, Fundação Educacional Serra dos Órgãos, RJ, Brasil.

6. Diplomado em Medicina, Fundação Educacional Serra dos Órgãos, RJ, Brasil. Médico Residente do Hospital Universitário Antônio Pedro, Universidade Federal Fluminense, RJ, Brasil.

Endereço para correspondência: Rodrigo Siqueira Batista. Fundação Educacional Serra dos Órgãos (FESO). Núcleo de Estudos em Filosofia e Saúde (NEFISA) - DPPE. Avenida Alberto Torres, 111 - Alto, CEP: 25964-000, Teresópolis-RJ, Brasil. E-mail: anaximandro@hotmail.com 


\section{INTRODUÇÃO}

A síndrome de imunodeficiência adquirida (AIDS) caracteriza-se por comprometimento progressivo da resposta imunológica, como consequiência da infecção pelo vírus da imunodeficiência humana (HIV). Inúmeros distúrbios reumáticos e fenômenos auto-imunes têm sido associados ao seu quadro clínico ${ }^{(1,2,3,4)}$, havendo relatos de acometimento musculoesquelético em até $72 \%$ dos $\operatorname{casos}^{(5)}$. Condições como síndrome de Reiter, artrites psoriásica e infecciosa, polimiosite, miopatias inflamatórias, síndrome de Sjögren, vasculites e fibromialgia podem ser a primeira manifestação clínica da infecção pelo HIV, devendo ser considerados como sinais de alerta para a classe médica ${ }^{(6,7,8)}$. Ademais, em alguns casos, as alterações reumáticas podem coincidir com o surgimento da $\operatorname{AIDS}^{(9,10,11)}$. Apesar de os achados reumatológicos serem reconhecidos há muitos anos, seus mecanismos de desencadeamento ainda não foram completamente esclarecidos, tratando-se, provavelmente, de diferentes processos fisiopatogênicos para as díspares anormalidades ${ }^{(12)}$. Estima-se que os distúrbios de natureza reumática associados ao HIV desenvolvam-se em três vertentes:

- imunologicamente mediadas, como nas artrites reativas, nas artrites psoriáticas e nas espondiloartropatias indiferenciadas;

- conseqüência da produção irregular de citocinas e da depleção de linfócitos T CD4+, tais como as artrites infecciosas e a osteomielite (por germes usuais e oportunistas);

- possivelmente como resultado direto da interação do HIV e o hospedeiro, como piomiosite, vasculites e síndrome linfocítica infiltrativa difusa.

Ainda que os quadros descritos ocorram também em enfermos imunocompetentes, geralmente o curso clínico é mais grave que o habitual, como no exemplo da artrite psoriásica ${ }^{(5)}$. Outra diferença importante repousa nas implicações terapêuticas, merecendo destaque a pobre resposta aos antiinflamatórios não-esteroidais (AINEs), devendo-se, muitas vezes, ser avaliado o uso de corticosteróides ou imunossupressores para controle das queixas ${ }^{(12)}$. Baseado nestas premissas, pretende-se, a seguir, discutir as principais alterações reumáticas presentes nos pacientes com infecção pelo HIV.

\section{ESPONDILOARTROPATIAS SORONEGATIVAS}

Estão entre as manifestações articulares de maior prevalência na população de pacientes infectados pelo HIV e $\operatorname{AIDS}^{(13,14,15)}$, acometendo-os com uma freqüência maior
TABELA 1

Principais MANIFESTAÇÕES REUMÁticas NOS PACIENTES INFECTADOS PELO HIV

\section{Artropatias e Distúrbios Relacionados}

Artrites reativas (incluindo a síndrome de Reiter)

Artrite psoriásica

Artrite séptica

Artrite associada à AIDS

Artralgias

Fibromialgia

Colagenoses e Miopatias

Polimiosite

Miosite associada à zidovudina

Piomiosite

Síndrome Linfocítica Infiltrante Difusa Síndrome (Sjögren-símile)

Lúpus eritematoso sistêmico

\section{Vasculites}

Vasculite necrosante

Vasculite similar à púrpura de Henoch-Schönlein

Vasculite por hipersensibilidade aos fármacos

Fenômenos de Auto-Imunidade

Anticorpos antinucleares

Anticorpos antiplaquetários

Anticorpos antilinfócitos

Testes de Coombs positivo

Anticorpos antifosfolipídios

Crioglobulinemia

que a encontrada na população em geral. Incluem-se neste grupo a artrite psoriásica, a espondilite anquilosante, as artrites relacionadas com as doenças inflamatórias intestinais e as artrites reativas. Com relação a estas últimas, surgem em $5 \%$ a $25 \%$ dos enfermos anti-HIV reatores, imediatamente antes ou de forma concomitante ao desenvolvimento da depressão imunológica. Outros estudos, entretanto, sugerem a ocorrência destas condições em estágios tardios da infecção pelo $\mathrm{HIV}^{(16,17)}$. A forma de apresentação mais comum, tanto nos indivíduos com infecção pelo HIV quanto nos não infectados, é uma oligoartrite grave e persistente, que afeta preferencialmente grandes articulações dos membros inferiores, associada à entesopatia ${ }^{(15,18)}$. Muitos doentes também têm outros aspectos clínicos associados como uretrites, conjuntivite, úlceras orais, balanite circinada e ceratodermia blenorrágica preenchendo os critérios diagnósticos da síndrome de Reiter ${ }^{(19,20)}$. Aproximadamente 30\% a 40\% dos 
pacientes apresentam resultados negativos na pesquisa do antígeno de histocompatibilidade HLA-B2 $7^{(16,21,22)}$.

Geralmente a resposta aos AINEs para controle das dores articulares não é satisfatória ${ }^{(17)}$, devendo ser avaliado o uso de corticosteróides e/ou imunossupressores, pesando-se os possíveis riscos do uso destes medicamentos, principalmente naqueles pacientes onde outras manifestações de imunodepressão ainda não tiverem ocorrido ${ }^{(16)}$.

Tem sido documentada a associação da infecção pelo HIV com a psoríase e artrite psoriásica ${ }^{(21)}$. O rash psoriasiforme parece ocorrer em pacientes infectados pelo HIV com a mesma freqüência que nos soronegativos, mas com maior gravidade. Costuma haver acometimento das articulações dos pés e tornozelos, com oligoartrite associada à entesopatia, dactilite e envolvimento ungueal, especialmente articulações das mãos e dos pés ${ }^{(15,19)}$. É também descrito o envolvimento da coluna vertebral e sacroileíte ${ }^{(15,19)}$. A artrite psoriásica em pacientes anti-HIV reatores tem um curso variável, porém, na maioria dos casos, tende a apresentar erosões e deformidades precoces, com evolução progressiva e refratariedade à terapia convencional ${ }^{(17)}$.

\section{ARTRITES INFECCIOSAS}

Foram relatados vários casos de artrite séptica, usualmente por organismos incomuns como Cryptococcus neoformans no joelho, Mycobacterium haemophilum no punho ${ }^{(23)} \mathrm{e}$ Sporothrix schenckii como sinovite crônica das articulações metacarpofalangianas ${ }^{(24)}$, além de Mycobacterium aviumintracellulare, Campylobacter fetus, Ureaplasma urealyticum e Histoplasma capsulatum ${ }^{(17)}$. Sem embargo, os agentes usuais estão comumente implicados, como o caso de Staphylococcus aureus $^{(25)}$, determinando artralgia, eritema e edema articular, especialmente nos usuários de drogas injetáveis ilícitas. O modelo clássico de apresentação de artrite monoarticular é ainda válido, porém, podem acontecer manifestações pouco usuais como tenossinovite por micobactérias não-tuberculosas.

Os casos de artrite em infectados pelo HIV - mormente se há doença em apenas uma articulação - devem ser conduzidos com punção articular, encaminhamento do material para Gram e cultura e início da terapia antimicrobiana de acordo com os resultados iniciais obtidos.

Tem sido aventada a existência de uma síndrome reumática específica, denominada artrite associada à $\operatorname{AIDS}^{(18,19)}$.
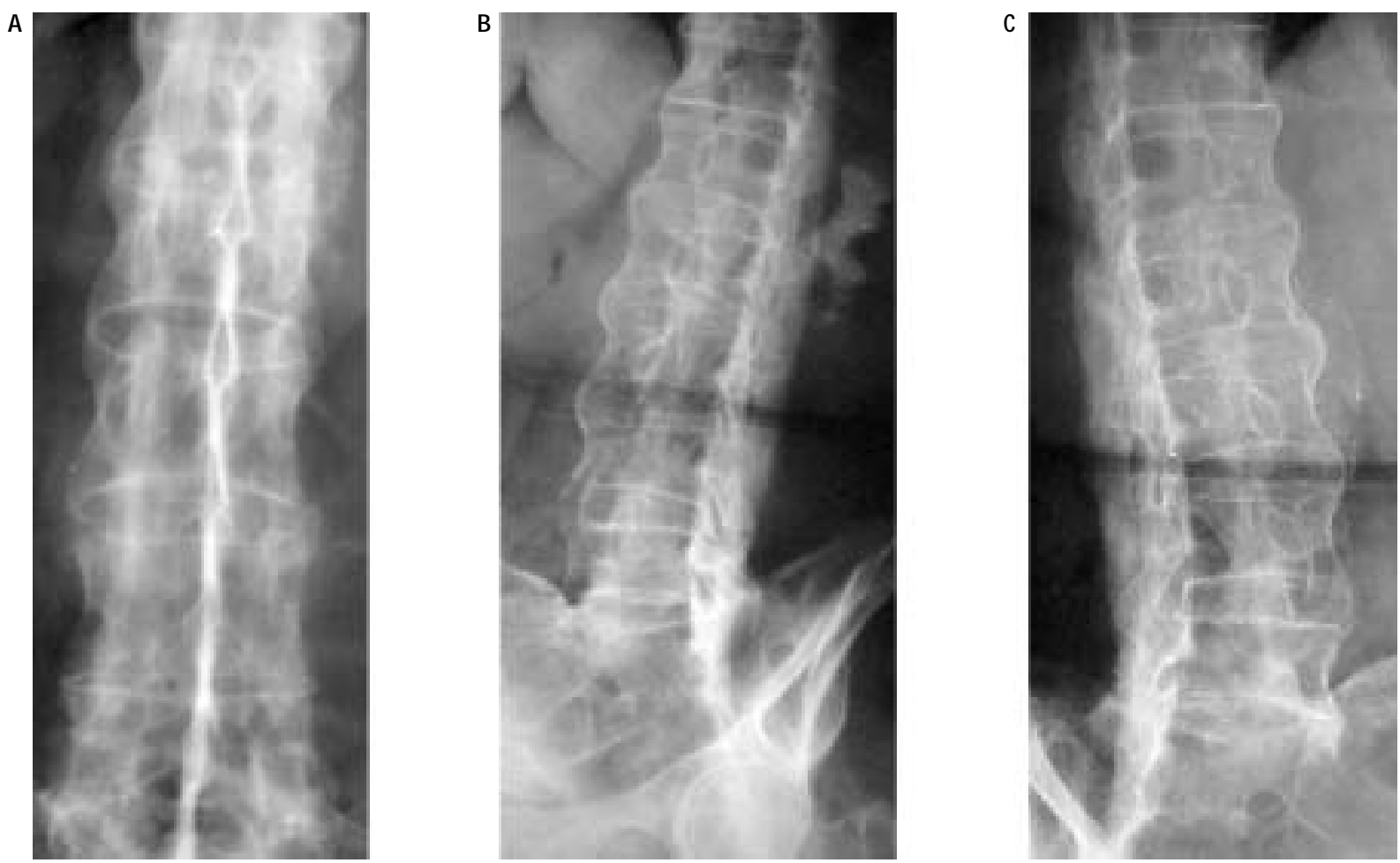

Figura 1 - Espondilite anquilosante. Radiografias da coluna lombar AP (A) e oblíquas (B e C). Note 0 apagamento dos espaços intervertebrais com anquilose dos corpos vertebrais e calcificação do ligamento longitudinal anterior. 
Caracterizada por oligoartrite não erosiva, subaguda, dolorosa, assimétrica na maioria das vezes, afetando principalmente joelhos e tornozelos. A análise do fluido sinovial indica um processo inflamatório agudo ${ }^{(17)}$. Geralmente não ocorrem relatos de antecedentes mórbidos - tais como distúrbios entéricos, geniturinários e infecções virais - e, tampouco, manifestações extra-articulares $^{(14)}$, ou positividade para o HLA-B27. A duração do quadro pode variar de uma a 24 semanas, sendo em média de 31 dias $^{(17)}$. O mecanismo fisiopatogênico da artrite associada à AIDS é desconhecido; todavia, especula-se sobre infecção viral direta da articulação ou artrite mediada por deposição de imunocomplexos ${ }^{(15)}$. Há boa resposta aos corticosteróides intra-articulares, com melhora da dor e dos sinais inflamatórios.

\section{ARTRALGIAS}

De um modo geral são as alterações mais encontradas em pacientes infectados pelo HIV, atingindo até 35\% destes enfermos. As artralgias costumam ser uma manifestação da síndrome de soroconversão pelo $\mathrm{HIV}^{(25)}$, ocorrendo em um terço dos $\operatorname{casos}^{(17)}$.

Afetando prioritariamente os joelhos e ombros - raramente as pequenas articulações -, foi também descrita uma síndrome de dor articular aguda, em até $10 \%$ dos pacientes com infecção pelo HIV, de curso intermitente, sem evidências de sinovite, caracterizada por curta duração, ocorrência de dores lancinantes, com pouca resposta aos AINEs, corticosteróides, ou analgésicos orais (incluindo opiáceos), requerendo às vezes o uso de opiáceos venosos ${ }^{(15,22,23)}$.

\section{FIBROMIALGIA}

A ocorrência de fibromialgia tem sido descrita em associação a várias infecções por agentes virais, como herpes vírus tipo 6, parvovírus B19, coxsackie B2 e HIV ${ }^{(17)}$. Em estudo realizado em 1992, estimou-se uma prevalência de 11\% de fibromialgia em pacientes anti-HIV reatores ${ }^{(27)}$. Esta associação parece estar relacionada com a ocorrência de depressão, condição reportada previamente em 50\% a 70\% dos enfermos estudados.

\section{MIOPATIAS}

As principais condições relacionadas com o HIV incluem as mialgias, as atrofias musculares, as poliomiosites e as piomiosites.

As mialgias são queixas relativamente presentes nos pacientes com infecção pelo HIV. Habitualmente são gene-
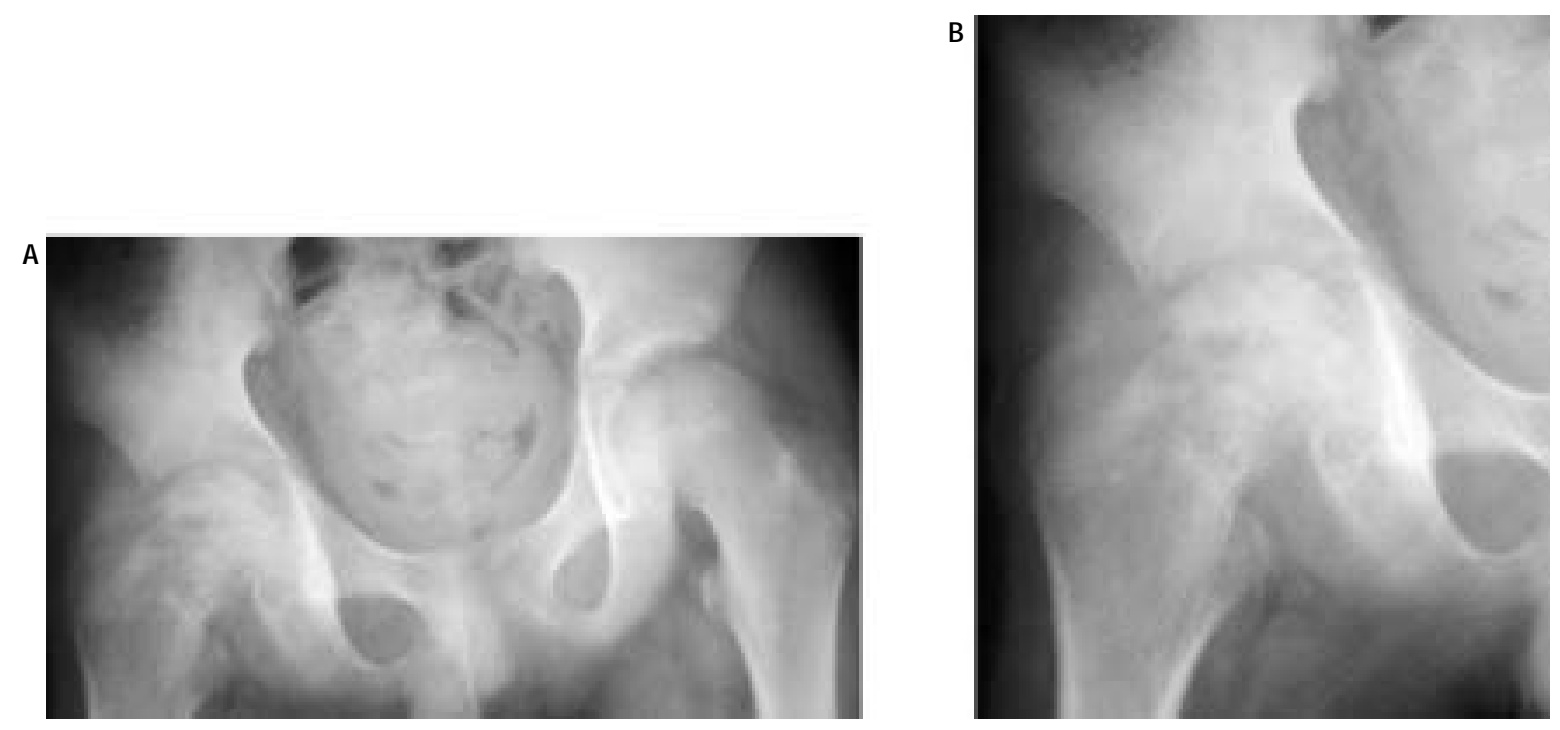

FIGURA 2 - Artrite infecciosa associada à osteomielite. Radiografia panorâmica da bacia em AP (A) e localizada da coxofemoral direita (B). Note os sinais da artrite infecciosa como aumento do volume das partes moles, redução do espaço articular, erosões ósseas e derrame articular, associado à esclerose endosteal e reação periosteal em razão de osteomielite. Compare a coxofemoral esquerda com a direita normal. 
ralizadas, recorrentes, com adequada resposta aos analgésicos comuns. Tem sido igualmente relatada atrofia muscular de diferentes graus, de caráter multifatorial, atribuída a alterações neurológicas, nutricionais e/ou infecciosas ${ }^{(17)}$, relacionada com a AIDS. O envolvimento muscular pode evidenciar-se meses ou anos após o início dos sintomas e sinais de imunossupressão, ou apresentar-se como a única manifestação ${ }^{(17)}$.

Com relação à polimiosite dois tipos principais já foram descritos: uma forma de apresentação precoce na infecção pelo HIV, idiopática ${ }^{(28)}$, com quadro clínico de evolução subaguda, caracterizada por fraqueza muscular proximal, mialgias intensas, níveis bastante elevados de creatinofosfoquinase (CPK), evidências de miopatia nos estudos eletromiográficos e achados de biópsia muscular compatíveis com polimiosite $^{(17,20,28)}$; e outra modalidade de disfunção muscular com aparecimento mais tardio, provavelmente relacionada com disfunção mitocondrial conseqüente ao uso dos inibidores da transcriptase reversa análogos dos nucleosídeos (ITRAN) - mormente zidovudina (AZT) e estavudina (d4T). Esta pode ser extremamente debilitante em algumas circunstâncias, com muitos enfermos respondendo apenas à administração de corticosteróides ${ }^{(20,28,29,30)}$. Observa-se rápida melhora se há suspensão do fármaco, podendo ser tentada a sua reintrodução após a resolução clínica e a normalização dos níveis das enzimas séricas ${ }^{(29)}$. A biópsia muscular fornece o diagnóstico, quando são visualizados fibras vermelhas, irregulares, e com mitocôndrias grandes e distorcidas.

São igualmente relatados casos de miosite desencadeada pelo próprio HIV, com sinais e sintomas similares aos quadros já descritos.

Alguns estudos sugerem ser a piomiosite mais freqüente em pacientes com infecção pelo $\mathrm{HIV}^{(20,31)}$. O músculo mais comumente afetado é o quadríceps e abscesso único está presente em 75\% dos casos. O agente etiológico implicado mais amiúde é o $S$. aureus. As principais manifestações incluem febre, dor muscular localizada e aumento de volume com consistência bastante endurecida. Normalmente há necessidade do uso de métodos de imagem (ultrasonografia, tomografia computadorizada ou ressonância magnética) para localização da coleção. As bases terapêuticas incluem antibioticoterapia - habitualmente oxacilina - e drenagem cirúrgica dos abscessos, quando presentes.

Outras modalidades de comprometimento muscular têm sido relatadas nos pacientes anti-HIV reatores, dentre elas miopatia necrótica não inflamatória, microsporidiose muscular e miosite ossificante ${ }^{(15)}$.
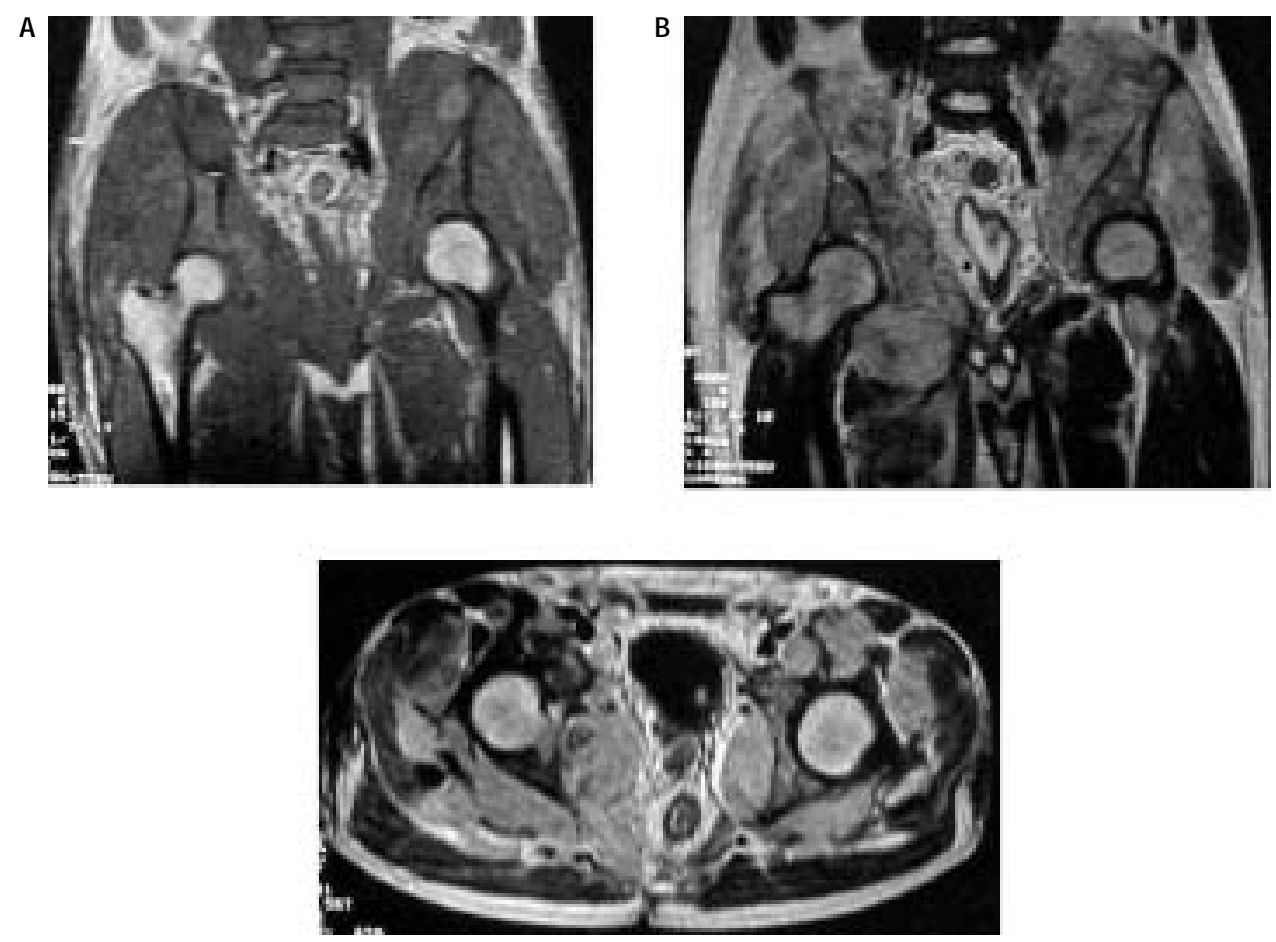

Figura 3 - Piomiosite. Ressonância magnética no plano coronal T1 (A) e T2 (B) e no plano axial T1 com gadolínio. Note o sinal heterogêneo da musculatura com intenso realce pelo contraste paramagnético. 


\section{VASCULITES}

Diferentes vasculites já foram identificadas em enfermos com infecção pelo HIV e AIDS $^{(15)}$. Há relatos de pacientes com vasculites inespecíficas, nas quais agentes outros, além do HIV, podem estar implicados, tais como o citomegalovírus (CMV), vírus das hepatites B e C, HTLV-I, vírus herpes simples e varicella-zoster, Epstein Barr e Pneumocystis carinii ${ }^{(14)}$. Uma forma clínica de vasculite necrótica, mais comumente do tipo poliarterite nodosa (PAN), vem sendo descrita, em alguns centros clínicos, como uma das formas mais freqüentemente relacionadas com o HIV ${ }^{(17,18)}$. Infecções virais, como as listadas acima, têm sido implicadas na patogênese da vasculite necrótica podendo, em alguns casos, ter um papel etiológico importante. A mononeurite múltipla secundária a este tipo de vasculite pode ser autolimitada, resolvendo-se espontaneamente, ou evoluir para polineuropatia sensorial e motora. A biópsia do nervo sural nestes pacientes evidenciou múltiplos focos de lesão neural com degeneração axonal, infiltrado endoneural e vasculite ${ }^{(17)}$. Foram descritos casos de vasculite de pequenas veias, que parecem ser freqüentes e podem ser enquadradas como púrpura de Henoch-Schönlein, e vasculites por hipersensibilidade a fármacos. Outros tipos de vasculites associadas à infecção pelo HIV incluem vasculite eosinofílica - com quadro clínico semelhante ao da arterite temporal -, granulomatose linfomatóide, angeíte linfocítica benigna, vasculite isolada do sistema nervoso central e linfoma angiocêntrico ${ }^{(17)}$.

\section{SÍNDROME LINFOCÍTICA INFILTRANTE DIFUSA (SJÖGREN-SÍMILE)}

Uma condição semelhante à síndrome de Sjögren foi descrita em enfermos com infecção pelo HIV ou por HTLV$1^{(32)}$, apresentando-se com grande aumento das parótidas associado à xerostomia, xeroftalmia e artralgias, geralmente coincidentes com o quadro de linfadenopatia generalizada persistente ${ }^{(33)}$. Tal quadro faz parte da síndrome linfocítica infiltrativa difusa (DILS), relacionada com a infecção pelo HIV, e que pode anteceder o aparecimento da AIDS. Tal quadro é diferenciável da síndrome de Sjögren clássica pela maior prevalência no sexo masculino, grande aumento das parótidas, freqüente infiltração linfocítica extraglandular, ausência de lesões epiteliais e de artrites, xeroftalmia menos intensa e não detecção de auto-anticorpos anti-Ro e antiLa séricos ${ }^{(14,15,33,34)}$. Ademais, enquanto na síndrome de Sjögren há predomínio de linfócitos T CD4+, na DILS observa-se preeminência dos linfócitos TDC8+ nos infiltrados tissulares. Os pacientes com DILS têm acometimento pulmonar, renal, neurológico e gastrintestinal mais graves, relatando-se também o risco de surgimento de linfomas de células B de glândulas salivares.

\section{LÚPUS ERITEMATOSO SISTÊMICO (LES)}

Alguns autores têm notado os muitos aspectos de similaridade entre a infecção pelo HIV e o LES ${ }^{(17,35,36)}$, os quais podem levar a dificuldades e erros no diagnóstico, destacando-se:

- erupção malar (nos pacientes anti-HIV reatores, atribuída normalmente à dermatite seborréica);

- desordens hematológicas como trombocitopenia imunologicamente mediada, leucopenia, linfopenia, neutropenia e anemia hemolítica Coombs positiva;

- proteinúria ao exame de urina tipo I e deposição de IgM e C3 em glomérulos renais;

- artralgia e artrites;

- síndrome de Sjögren-símile e vasculites;

- quadro constitucional com febre, linfadenopatia, emagrecimento;

- positividade para anticorpos antifosfolipídios, complexos imunes circulantes, hipergamaglobulinemia;

- manifestações neurológicas: mononeurites múltiplas, cefaléia, convulsões, neuropatia de pares cranianos e periférica.

Outro aspecto de possível confusão diagnóstica é a propensão das várias doenças reumáticas a formar autoanticorpos, que podem reagir, de modo cruzado, com o HIV, produzindo resultados falso-reativos nos testes anti$\mathrm{HIV}^{(16)}$; a conduta frente a esses casos deve ser a confirmação destes resultados através da realização do exame de Westernblot, prática de rotina para a caracterização da infecção pelo HIV ${ }^{(14,15,20)}$.

Embora apresentando aspectos coincidentes, tem havido poucos relatos de casos de ocorrência simultânea. Especulase que a imunodepressão acentuada em decorrência da infecção pelo HIV poderia atenuar as manifestações clínicas do LES, tornando esse diagnóstico menos óbvio. Já foram reportados pacientes cujas manifestações lúpicas melhoraram com a progressão da imunodeficiência ${ }^{(15,36)}$, assim como reaparecimento das manifestações com a introdução de anti-retrovirais ${ }^{(17)}$.

\section{OUTROS FENÔMENOS AUTO-IMUNES}

Diversos auto-anticorpos, incluindo anticorpos antinucleares, antiplaquetários, antilinfocíticos, antigranulocíticos e antifosfolipídios (anticardiolipina e anticoagulante lúpico), bem como imunocomplexos, fator reumatóide e crioglobulinas estão associados ao $\operatorname{HIV}^{(12,37)}$. 
Vários fenômenos têm sido associados com a infecção pelo HIV, como a positividade para anticorpos antinucleares, anticorpos antiplaquetários, antigranulócitos ${ }^{(17)}$, antilinfócitos e relatos de testes de Coombs positivo, embora nem sempre associado à hemólise clínica ${ }^{(38,39)}$. Investigações têm demonstrado que até $20 \%$ dos enfermos apresentam anticorpos; sem embargo, a positividade para a presença de anticoagulante lúpico - um anticorpo antifosfolipídio pode chegar a $45 \%^{(15,40,41)}$. Pacientes com AIDS que apresentam este auto-anticorpo manifestam um prolongamento no tempo de sangramento e tempo de ativação de protrombina, bem como trombocitopenia ${ }^{(15)}$. Contrastando com os pacientes anti-HIV não reatores, não são descritos casos de trombose recorrente. A presença de anticoagulante lúpico tem sido associada com algumas infecções agudas, especialmente pneumonia por $P$. carinii ${ }^{(15)}$. Em alguns casos a resolução da pneumocistose seguiu-se de desaparecimento da atividade deste auto-anticorpo ${ }^{(24)}$.

$O$ anticorpo anticardiolipina ${ }^{(17)}$ também tem sido encontrado em uma alta porcentagem em pacientes infec-

\section{REFERÊNCIAS}

1. Keat A: Human immunodeficiency virus infection and the rheumatologist. Ann Rheum Dis 48:346-53, 1989.

2. Vassilopoulos D, Prassad C, Jurado R, Workowski K, Agudelo C: Musculoeskeletal infections in patients with human immunodeficiency vírus infection. Medicine 76:284-94, 1997.

3. Espinoza LR: Rheumatic manifestations in populations at risk for HIV infection: the added effect of HIV. Rheumatol 18:10, 1991.

4. Stein MC, Davis P: Arthritis associated with HIV infection in Zimbabue. Rheumatol 23:3, 1996.

5. Neder SS, Bonfiglioli R, Provenza JR, Neto JFM, Sâmara AM: Reiter como Manifestação Inicial da Síndrome de Imunodeficiência Adquirida. Rev Bras Reumatol 31:5, 1991.

6. Cuellar ML, Espinosa LR: Rheumatic manifestations of HIV-AIDS. Baillieres Best Pract Res Clin Rheumatol 14:579-93, 2000.

7. Medina Rodriguez F: Rheumatic manifestations of human immunodeficiency virus infection. Rheum Dis Clin North Am 29:145-61, 2003.

8. Reveille JD: The changing spectrum of rheumatic disease in human immunodeficiency virus infection. Semin Arthritis Rheum 30: 147-66, 2000.

9. Marquez J, Restrepo CS, Candia L, Berman A, Espinoza LR: Human immunodeficiency virus-associated rheumatic disordes in the HAART era. J Rheumatol 31:741-6, 2004.

10. Solinger AM: Rheumatic manifestations of human immunodeficiency virus. Curr Rheumatol Rep 5:205-9, 2003.

11. Tehranzadeh J, Ter-Oganesyan RR, Steinbach LS: Musculoskeletal disorders associated with infection and AIDS. Part I: infectious musculoskeletal conditions. Skeletal Radiol 33:249-59, 2004. tados pelo HIV, embora não fosse observada uma associação entre anticorpos anticardiolipina e sangramento ou presença de anticoagulante lúpico. Acredita-se ser a formação desses auto-anticorpos uma forma de resposta imunológica às infecções. Por fim, tem havido relatos de detecção de crioglobulinemia em pacientes infectados pelo HIV, marcante em associação com os vírus da hepatites B e $\mathrm{C}^{(19,42,43)}$.

\section{CONSIDERAÇÕES FINAIS}

Este artigo reviu as correlações mais importantes entre as doenças reumáticas e a infecção pelo HIV, enfatizando os pontos de maior relevância para a prática diária do reumatologista. Espera-se, com este estudo, que a difusão de conhecimentos possa facilitar, em alguma medida, o diagnóstico e o tratamento dos enfermos com AIDS, aprimorando suas qualidades de vida, o que, em última análise, representa a missão maior daqueles que se dedicam à medicina.

12. Fauci AS, Lane HC: Doença devida ao vírus da imunodeficiência humana (HIV): AIDS e distúrbios relacionados. Braunwald E, Fauci AS, Kasper DL, Hauser SL, Longo DL, Jameson JL: Harrison Medicina Interna. 15a ed, Rio de Janeiro, Mc Graw Hill, 2002, p. 1963-2026.

13. Guerra JEH, Geller M, Alves OAT, Squeff FA: Aspectos clínicos e imunogenéticos da Síndrome de Reiter. Rev Bras Med 59: 696-702, 2002.

14. Berman A, Spinoza LR, Diaz JO: Rheumatic manifestations of human immunodeficiency virus infection. Am J Med 85:59-64, 1988.

15. Kaye BR: Rheumatologic manifestations of infection with human immunodeficiency virus (HIV). Ann Int Med 111:158-67, 1989.

16. Espinoza LR: Rheumatic manifestations associated with human immunodeficiency vírus infection. Arthritis and Rheumatism 32:1615-22, 1989.

17. Espinoza LR: There is an association between human immunodeficiency virus infection and spondyloarthropathies. Rheum Dis Clin North America 18: 257-66, 1992.

18. Riynes RI, Goldenberg DL, Di Giacomo R, Olson R, Hussain M, Keausy J: Acquired Immunodeficiency Syndrome associated arthritis. Am J Med 84:810-6, 1988.

19. Mandell GR, Bennet JE, Dolin R: Principles and Practice of Infections Diseases. 5th ed, Philadelphia:W.B. Saunders Company, 2000, p. 3282.

20. Gomes AP, Siqueira-Batista R, Rachid M: Síndrome de Imunodeficiência Adquirida. In: Siqueira-Batista R, Gomes AP, Santos SS, Almeida LC, Figueiredo CES, Bedoya Pacheco SJ: Manual de Infectologia. Rio de Janeiro: Revinter, 2003, p. 169-89.

21. Durvie M, Johnson TM, Rapini RP, Freese T, Brewton G, Rios A: Acquired Immunodeficiency Syndrome associated psoriasis and Reiter's syndrome. Arch Dermatol 123:1622-32, 1987. 
22. Foster SM, Seifert MH, Keat AC: Inflamatory joint disease and human immunodeficiency virus infection. Br Med J 296:1625-7, 1988.

23. Rogers PL, Walker RE, Lane HCl: Disseminated Mycobacterium haemophilum infection in two patients with Acquired Immunodeficiency Syndrome. Am J Med 84:640-2, 1988.

24. Lipstein-Kresch E, Isenberg HD, Singer C, Cooke O, Greenwald RA: Disseminated Sporothrix schenckii infection with arthritis in a patient with Acquired Immunodeficiency Syndrome. J Rheumatol 12:805-8, 1985

25. De-Maria-Moreira NL, Amorim DS, Vieira RMR, et al: Infecções por Staphylococcus aureus. Relato de caso e discussão da literatura. J Bras Med 82:81-93, 2002.

26. Cooper DA, Gold J, McClean P: Acute AIDS retrovirus infection. Definition of a clinical ilness associated with seroconversion. Lancet 1:637-640, 1985

27. Simms RW: Fibromyalgia syndrome in patients infected with human immunodeficiency virus. Am J Med 92:368-74, 1992.

28. Dalakas MC, Pezeshkpour GH, Gravell M, Server JL: Polymyositis associated with AIDS retrovirus. JAMA 256:2381-3, 1986.

29. Bessen LJ, Greene JB, Loule E, Seitzman P, Weineberg H: Severe polymyositis-like syndrome associated with zidovudine therapy of AIDS and ARC. N Engl J Med 318:708, 1988.

30. Schechter M, Marangoni DV: Doenças Infecciosas: conduta diagnóstica e terapêutica. 2a ed, Rio de Janeiro, Guanabara Koogan, 1998, p. 674.

31. Watts RA, Hoffbrand BI, Paton DF, Davis JC: Pyomyositis associated with human immunodeficiency virus infection. Br Med J 294: 1524-5, 1987.

32. Courderc LJ, D’ Agay MF, Damon F, Harzic M, Brocheriou C, Caluvel JP: Sicca complex and infection with human immunodeficiency virus. Arch Int Med 147:898-901, 1987.
33. Monte-Alto CR, Guerra JEH, Squeff F, Lima O, Gomes AP, Siqueira Batista R: Síndrome de Sjögren. J Bras Med 82:46-52, 2002.

34. Rachid M, Schechter M: Manual de HIV/AIDS. 7 ed, Rio de Janeiro: Revinter, 2003, p. 230.

35. De Clerck LS, Couttenye MM, De Broc ME, Stevens WJ: Acquired immunodeficiency syndrome mimicking Sjogren's syndrome and systemic lupus erythematosus. Arthritis and Rheumatism 31:272-5, 1988.

36. Daikh BE, Holyst MM: Lupus-specific autoantibodies in concomitant human immunodeficiency virus and systemic lupus erythematosus: case report and literature review. Semin Arthritis Rheum 30:418-25, 2001.

37. Asherson RA, Cervera R: Antiphospholipid antibodies and infections. Ann Rheum Dis 62:388-93, 2003.

38. Dorset B, Cronin W, Chuma V, Joachim HL: Anti-lymphocyte antibodies in patients with Acquired Immunodeficiency Syndrome. Am J Med 78:621-6, 1985.

39. Kopelman RH, Zolla-Pazner S: Association of human immunodeficiency virus infection and autoimmune phenomenon. Am J Med 84:82-8, 1988.

40. Bloom EJ, Abrams D, Rodgers G: Lupus anticoagulant in the acquired immunodeficiency syndrome. JAMA 256:491-3, 1986.

41. Le Frere JJ, Gozin D, Modal J, Vittervy D: Circulating anticoagulant in the Acquired Immunodeficiency Syndrome. Ann Inter Med 107:429-30, 1987.

42. Almeida EPT: Manifestações reumatológicas da AIDS. In: SiqueiraBatista R, Gomes AP, Igreja RP, Huggins DW: Medicina Tropical. Abordagem Atual das Doenças Infecciosas e Parasitárias. Rio de Janeiro: Cultura Médica, 2001, p. 833-6.

43. Siqueira-Batista R, Gomes AP, Igreja RP, Bedoya Pacheco SJ: Hepatites virais. In: Siqueira-Batista R, Gomes AP, Santos SS, Almeida LC, Figueiredo CES, Bedoya Pacheco SJ: Manual de Infectologia. Rio de Janeiro: Revinter, 2003, p. 216-222. 